\title{
O estado de coisas inconstitucional: um estudo de caso sobre a ADPF
} 347

O presente trabalho busca uma teorização a respeito do Estado de Coisas Inconstitucional, sendo esse um instrumento utilizado como forma de combater a omissão estatal a fim de garantir direitos fundamentais básicos. O citado instrumento é comumente utilizado pela corte colombiana, porém no Brasil foi citado em uma decisão judicial pela primeira vez na ADPF 347 em agosto de 2015, quando o STF reconheceu violação de direitos no que se refere ao sistema prisional, ainda não é possível ter uma visão sobre seus efeitos, devido os comandos da corte serem de médio e longo prazo, no entanto a citada teoria vem causando muitos debates no meio jurídico, principalmente no que se refere ao ativismo judicial.

Palavras-chave: Omissão estatal; Falhas estruturais; Ativismo judicial.

\section{The unconstitutional state of things: a case study on ADPF 347}

The present work seeks a theorizing about the State of Things Unconstitutional, which is an instrument used as a way to combat state omission in order to guarantee basic fundamental rights. The aforementioned instrument is commonly used by the Colombian court, but in Brazil was cited in a court decision for the first time in ADPF 347 in August 2015, when the STF acknowledged a violation of rights with regard to the prison system, it is not yet possible to have a view on its effects, due to the commands of the court are medium and long term, however the aforementioned theory has been causing much debate in the legal environment, especially with regard to judicial activism.

Keywords: State omission; Structural failures; Judicial activism.

Topic: Direito Constitucional

Reviewed anonymously in the process of blind peer.

Rafael Rocha Silva (ic

Universidade Tiradentes, País

http://lattes.cnpq.br/3956542711437931

http://orcid.org/0000-0002-1283-3283

rafael rocha3112@hotmail.com
Received: 11/06/2019

Approved: 23/11/2019
Referencing this:

SILVA, R. R.. O estado de coisas inconstitucional: um estudo de caso sobre a ADPF 347. Libro Legis, v.1, n.2, p.11-16, 2019. DOI: http://doi.org/10.6008/CBPC2674-6409.2019.002.0002

DOI: 10.6008/CBPC2674-6409.2019.002.0002 


\section{INTRODUÇÃO}

O presente estudo surge da necessidade de entendermos o Estado de Coisas Inconstitucional, fazendo uma reflexão acerca dos efeitos de sua declaração e buscando na doutrina e na jurisprudência fontes de debates e conhecimento acerca do proposto tema. De acordo com Campos (2016), "a ideia é a de correlacionar a omissão com a verificação de falhas da atuação concreta dos dispositivos constitucionais a revelar tutela insuficiente de direitos".

Nessa perspectiva se faz necessário desenvolver conhecimento acerca da recente decisão do STF na ADPF 347, em que foi reconhecido o $\mathrm{ECl}$ na seara do sistema prisional brasileiro. Diante do exposto será estudado os efeitos da declaração do $\mathrm{ECl}$, desenvolvendo uma análise crítica a partir de ideias desenvolvidas pela jurisprudência e doutrina brasileira e estrangeira.

Dentro desse contexto, questiona-se: qual a importância do julgamento da ADPF 347 para a proteção dos direitos fundamentais no Brasil e quais os efeitos práticos da citada decisão? Será que o citado instituto será eficiente para sanar as falhas estruturais do sistema carcerário brasileiro, a ponto de ter suas ordens e orientações respeitadas pelas autoridades responsáveis pelo cumprimento das metas?

Nesse sentido, esta pesquisa tem como objetivos: a) analisar quais as consequências do julgamento da ADPF 347 para a proteção dos direitos fundamentais elencados na Constituição Federal de 1988; b) Compreender o Estado de Coisas Inconstitucional e a sua aplicabilidade no ordenamento jurídico brasileiro; c) Identificar as principais falhas estruturais dos presídios brasileiros e quais as consequências sociais da omissão estatal que acaba por violar direitos fundamentais básicos, não só dos presos como da sociedade em geral.

Justifica-se este trabalho devido a importância de apresentar as prováveis afrontas à direitos fundamentais protegidos pela CF/88 que levou a decretação do Estado de Coisas Inconstitucional dos presídios brasileiros pelo Supremo Tribunal Federal. Proporcionando assim uma base conceitual para que seja possível o desenvolvimento de ideias voltadas a resolução da omissão estatal, e por consequência dos problemas que assolam o sistema carcerário brasileiro.

É visível a afronta a direitos fundamentais decorrente das péssimas condições dos presídios brasileiros, essa violação não ocorre apenas intramuros, mas também extramuros, chegando a prejudicar a sociedade como um todo. As consequências da falência do sistema prisional brasileiro são gritantes, já que as negações a direitos fundamentais acabam por embrutecer os integrantes desse sistema, por consequência reflete no aumento da violência em todo o país.

No Brasil ainda é tímido os estudos referentes ao $\mathrm{ECl}$, talvez pelo fato de ser uma decisão recente ou até pela desmotivação em se garantir direitos fundamentais. $O$ fato é que o presente estudo parte da premissa que os direitos fundamentais são inerentes a todos os seres humanos e não apenas a uma parcela selecionada no berço. O Estado de Direito garante direitos e obrigações que devem ser estritamente respeitados por todas as pessoas, inclusive e principalmente pelo próprio estado.

Nessa perspectiva faz-se necessário a aquisição de informações para observar como a citada decisão 
do STF será recepcionada e trabalhada pelos órgãos responsáveis por estabelecer os comandos emitidos pela corte, avaliando a possível aplicabilidade de tal teoria em outras situações que afrontem de forma gritante os direitos e garantias previstos em nossa constituição. O presente estudo será desenvolvido por meio de uma pesquisa qualitativa, onde serão analisados meios bibliográficos e documentais. Será utilizado para a coleta de dados principalmente a doutrina e a jurisprudência, de forma a introduzir um viés crítico ao trabalho produzido.

\section{METODOLOGIA}

\section{0 que é o 'estado de coisas inconstitucional’?}

O Estado de Coisas Inconstitucional (ECI) surgiu na corte suprema colombiana e se fundamenta com base na omissão estatal referente a ineficácia legislativa ou ineficiência executiva quanto a garantia de direitos fundamentais. Nesse sentido leciona Campos (2015):

O descumprimento do dever de legislar ou de expedir normas regulamentadoras decorreria da inércia dos poderes políticos, máxime o legislador, em criar as condições necessárias para o gozo efetivo dos direitos fundamentais, ou em deixar de afastar ou minimizar os obstáculos reais, as limitações fáticas que impeçam a fruição desses direitos, e isso independentemente da tipologia ou especificidade dos enunciados constitucionais.

O Estado de Coisas Inconstitucional surge com o fito de garantir diretos fundamentais básicos, a corte colombiana reconheceu pela primeira vez o $\mathrm{ECl}$ em uma situação em que os professores estavam sofrendo constantes lesões no que se refere ao sistema previdenciário por parte das autoridades públicas, a partir daí a corte começou a reconhecer o $\mathrm{ECl}$ em diversas outras decisões, apresentando um ativismo judicial para garantir a manutenção das garantias fundamentais.

O Estado de Coisas Inconstitucional tem origem nas decisões da Corte Constitucional Colombiana (CCC) diante da constatação de violações generalizadas, contínuas e sistemáticas de direitos fundamentais. Tem por finalidade a construção de soluções estruturais, dialógicas e pactuadas voltadas à superação desse lamentável quadro de violação massiva de direitos das populações vulneráveis em face de ações e omissões lesivas do poder público. (CUNHA JUNIOR, 2016).

Para ser caracterizado o $\mathrm{ECl}$ é necessário a observância de determinados critérios que foram muito bem formulados por Cunha Junior (2016),

(a) é grave, permanente e generalizada a violação de direitos fundamentais, que afeta a um número amplo e indeterminado de pessoas (na hipótese, não basta uma proteção insuficiente);

(b) há comprovada omissão reiterada de diversos e diferentes órgãos estatais no cumprimento de suas obrigações de proteção dos direitos fundamentais, que deixam de adotar as medidas legislativas, administrativas e orçamentárias necessárias para evitar e superar essa violação, consubstanciando uma falha estrutural das instâncias políticas e administrativas (isto é, não basta, para caracterizar o ECl, a omissão de apenas um órgão ou uma autoridade);

(c) existe um número elevado e indeterminado de pessoas afetadas pela violação; $\underline{\mathrm{e}}$

(d) há a necessidade de a solução ser construída pactuada (solução dialógica) pela atuação conjunta e coordenada de todos os órgãos envolvidos e responsáveis, de modo que a decisão do Tribunal - que se reveste de natureza estrutural, na medida em que envolve uma pluralidade de providências - é dirigida não apenas a um órgão ou autoridade, mas sim a uma pluralidade órgãos e autoridades, visando à adoção de mudanças 
estruturais (como, por exemplo, a elaboração de novas políticas públicas, a alocação ou remanejamento de recursos públicos, obrigações de fazer ou de não fazer, etc.).

Todo cidadão deve cumprir seus deveres como devem gozar dos seus direitos garantidos na constituição federal, problema grave surge quando o estado não cumpre o seu papel de legislar e executar políticas públicas que venham a garantir direitos fundamentais básicos, causando assim um efeito dominó nos pilares da sociedade, pois se uma pessoa não tem direitos, a mesma não quer ter obrigações, ou pior, muitas vezes é obrigada a infringir obrigações para sobreviver.

Para entendermos melhor o que é o ECl, Campos (2016), explica que esse instrumento serve para a corte ir de encontro contra a realidade inconstitucional decorrente da omissão estatal, com o fito de acusar as falhas estruturais que implicam na violação de direitos fundamentais, agindo de forma ativa para transformar a realidade social contrária a constituição.

\section{DISCUSSÃO TEÓRICA}

\section{As falhas estruturais do sistema prisional brasileiro que levaram a decretação do estado de coisas inconstitucional}

É pertinente iniciar as considerações sobre as falhas estruturais do sistema prisional trazendo à tona a visível ausência de compromisso por parte do Estado, Estado esse que se omite no que se refere às garantias fundamentais básicas do preso, importante ressaltar que o caminho até a delinquência perpassa também pela omissão de políticas públicas voltadas aos setores básicos de desenvolvimento social.

Como leciona Greco (2016), o problema carcerário brasileiro nunca ocupou a pauta de preocupação dos governantes, exceto quando o problema vem à tona através de denúncias de organizações não governamentais e da explosão de grandes rebeliões que venham a transparecer a realidade cruel dos presídios brasileiros.

Interessante observar e refletir que o problema não é intramuros, pois a gravidade da situação perpassa por problemas sociais, os poderes já se mostraram ineficazes em resolver, a exemplo dos péssimos índices de avaliação da educação básica, o desemprego e a consequente diminuição de renda, a elevação do consumo de drogas, entre outros fatores que tem como consequência o aumento da violência.

No Brasil, existem diferentes setores sociais nos quais se podem apontar violações sistemáticas de direitos fundamentais decorrentes de falhas estruturais, a começar por políticas públicas insuficientes: saneamento básico, saúde pública, consumo de crack. Atualmente, talvez seja o sistema carcerário brasileiro o que produz o maior grau de violação generalizada de direitos humanos decorrente de omissões e falhas estruturais e agravada pela sistemática inércia e incapacidade das autoridades públicas em superar tal quadro. (CAMPOS, 2016).

Muitas vezes a inércia e incapacidade das autoridades em resolver tal quadro estão ligadas ao clamor popular de que o preso deve sofrer, clamor esse potencializado pela mídia que usa tal situação como forma de ganho de audiência e consequentemente poder e lucro. Fato mais grave dessa omissão está atrelada a corrupção sistêmica entranhada no sistema político brasileiro, impossibilitando claramente a garantia de direitos fundamentais básicos. Streck (2013) resume esse sistema como "uma verdadeira casta que assume o controle do Estado, governando-o de acordo com seus interesses". 
Podemos apontar como uma evidente falha estrutural que agrava o sistema carcerário brasileiro, a seletividade do direito penal. Dados do Ministério da justiça (2014), apontam que o Brasil tem a quarta maior população carcerária do mundo, atrás apenas de EUA, China e Rússia, o citado relatório evidencia também que o sistema carcerário brasileiro é composto basicamente por negros, pessoas de baixa escolaridade e baixa renda, trazendo à tona reflexos de uma sociedade desigual.

A observação sociológica indica que o direito penal funciona de maneira seletiva e garante a estabilidade da ordem capitalista. É um direito da classe dominante tanto no micronível (pessoas envolvidas como réu e presos) como no macronível (função social-objetiva de seu funcionamento). Para tanto, recorre-se à brutalidade. (DIMOULIS, 2016).

A real situação das afrontas aos direitos fundamentais previstos na constituição deve ser analisada a luz da responsabilidade político-criminal que permeia nosso ordenamento, é obvio que atitudes mais drásticas em relação ao não encarceramento assustam as pessoas, no entanto fica visível que o atual formato do sistema é falho e só vem a potencializar mais ainda a problemática social relacionada à violência, até por que não se percebe o intuito de ressocializar, apenas o de punir, desde que essa punição atinja apenas uma parte da sociedade, geralmente escolhidas em meio a locais carentes de políticas públicas devido a completa ineficiência e omissão estado.

O estado atual dos cárceres diz da forma como a sociedade brasileira resolveu historicamente suas questões sociais, étnicas, culturais, ou seja, pela via da exclusão, da neutralização, da anulação da alteridade. Diz da violência hiperbólica das instituições, criadas no projeto moderno para trazer felicidade às pessoas (discurso oficial), mas que reproduzem - artificialmente, embora com inserção no real - a barbárie que a civilização tentou anular. Diz da falácia dos discursos políticos, dos operadores do direito e da ciência (criminológica), sempre perplexos com a realidade e ao mesmo tempo receosos, temerosos, contidos, parcimoniosos frente às soluções radicais (anticarcerárias), pois protegidos pela repetição da máxima de prisão como solução necessária. (CARVALHO, 2013).

O modelo de sistema prisional exposto trata o ser humano com descartável, e não me refiro apenas dos encarcerados, estou falando de todos os seres humanos, exceto os que foram selecionados a poder ter direitos à saúde, educação, segurança, trabalho e remuneração, lazer, meio ambiente saudável, entre outros fatores que deveriam ser inerentes a formação da personalidade e qualidade de vida de todas as pessoas.

\section{Estado de coisas inconstitucional $\mathbf{x}$ ativismo judicial}

No Brasil, com o reconhecimento da ADPF 347, reconhece um ECI no que se refere à situação do sistema prisional e acaba por abrir precedentes para reconhecimento em situações futuras. Apesar de novo o tema, já existe divergências doutrinárias interessantes, principalmente no que tange ao ativismo judicial, em que há um debate acerca de uma possível violação à separação dos poderes e uma ameaça à democracia.

Nesse sentido Streck (2016) faz uma interessante reflexão acerca dos perigos desse ativismo, lecionando que:

O próprio nome da tese (Estado de Coisas Inconstitucional - ECI) é tão abrangente que é difícil combatê-la. Em um país continental, presidencialista, em que os poderes Executivo e Legislativo vivem às turras e as tensões tornam o Judiciário cada dia mais forte, nada melhor do que uma tese que ponha "a cereja no bolo", vitaminando o ativismo, cujo conceito e sua diferença com a judicialização estão desenvolvidos em vários lugares. (STRECK, 2016). 
Em sentido contrário Campos (2015), ensina que não se trata de usurpação de poderes, mas sim de promoção de diálogos democráticos entre os poderes e a sociedade, para que juntos possam chegar à melhores soluções. Acontece que, assim como ocorreu na corte colombiana, o STF poderá decretar ECI em vários outros setores da sociedade, pois visivelmente percebemos afronta a direitos garantidos na carta magna no sistema de saúde, na educação, entre outros setores de suma importância para garantir a dignidade da pessoa humana. Streck (2016), faz uma dura crítica ao ECl afirmando que a execução de políticas públicas está à disposição do executivo e não do judiciário, complementando que não dá para fazer um estado social com base em decisões judiciais.

Campos (2015) defende o instituto afirmando que "o ECI busca soluções a partir de medidas a serem tomadas por diversos órgãos mediante ordens flexíveis sem que conste formulações diretas de políticas públicas, as orientações são para superar os bloqueios políticos e institucionais que acabam por agravar as violações massivas de direitos fundamentais". Tese essa que concordamos com plenitude. Necessário lembrar que o STF é o guardião da constituição, dessa forma que é viável a adoção de instrumentos eficazes para combater as omissões inerentes aos direitos protegidos pela nossa carta maior.

\section{CONCLUSÕES}

O Estado de Coisas Inconstitucional por ser uma teoria bastante nova acaba por gerar receio no que se refere a sua aplicação. O melhor entendimento sobre o assunto irá possibilitar um maior debate e consequentemente o melhor aperfeiçoamento do presente instrumento. $\mathrm{Na}$ corte colombiana o $\mathrm{ECl}$ já mostrou seus efeitos, uns positivos outros nem tanto, já no Brasil é muito recente a decisão da ADPF 347, não podendo assim mensurar sobre seus efeitos. Deste modo cabendo aos pesquisadores da área apenas observar o desenrolar das futuras decisões e verificar se suas ordens estão sendo respeitadas e cumpridas pelos agentes políticos responsáveis pela execução das políticas públicas.

Vale ressaltar que vivemos em um país de grande dimensão e com grandes e graves problemas estruturais a serem sanados, e toda forma de conhecimento que venha a contribuir será bem-vinda, o Direito não pode ficar omisso ao desenvolvimento da sociedade brasileira, deve-se penetrar nos debates de forma a contribuir para a formação de uma sociedade mais justa, igualitária e solidária.

\section{REFERÊNCIAS}

CAMPOS, C. A. A.. Estado de Coisas Inconstitucional. Salvador: JusPodivm, 2016.

CAMPOS, C. A. A.. Devemos temer o 'estado de coisas inconstitucional’?. São Paulo: CONJUR, 2015.

CARVALHO, S.. Em da lei de responsabilidade políticocriminal: o caso do anteprojeto de código penal. In: GRECO, R.. Comentários ao Projeto do Novo Código Penal (PLS 236/2012). Niterói: Impetus, 2013.

CUNHA JUNIOR, D.. O Estado de Coisas Inconstitucional como garantia de direitos fundamentais. 2016.
DIMOULIS, D.. Direito Penal Constitucional: Garantismo na Perspectiva do Pragmatismo Jurídico-Político. Belo Horizonte: Arraes, 2016.

GRECO, R.. Sistema Prisional: colapso atual e soluções alternativas. 3 ed. Niterói: Impetus, 2016

STRECK, L. L.. Bem jurídico no estado democrático de direito: 'Todavía' La ley ES como La serpiente; solo pica a los descalzos?. In: GRECO, R.. Comentários ao Projeto do Novo Código Penal (PLS 236/2012). Niterói: Impetus, 2013.

STRECK, L. L.. Estado de Coisas Inconstitucional é uma nova forma de ativismo. CNJ, 2016.

A CBPC - Companhia Brasileira de Produção Científica (CNPJ: 11.221.422/0001-03) detém os direitos materiais desta publicação. Os direitos referem-se à publicação do trabalho em qualquer parte do mundo, incluindo os direitos às renovações, expansões e disseminações da contribuição, bem como outros direitos subsidiários. Todos os trabalhos publicados eletronicamente poderão posteriormente ser publicados em coletâneas impressas sob coordenação da Sapientiae Publishing, da Companhia Brasileira de Produção Científica e seus parceiros autorizados. Os (as) autores (as) preservam os direitos autorais, mas não têm permissão para a publicação da contribuição em outro meio, impresso ou digital, em português ou em tradução. 